between domains in the three configurations. Inter-domain approaches were excluded. I agree that the establishment and classification of contacts are subjective and regard these uncertainties as partially responsible for the scatter on the graphs in Fig. 11 of the Paper. Nevertheless, I believe that the exercise was a necessary element of the concept under investigation.

\title{
REFERENCES
}

Schofield, R. K. \& Samson, H. R. (1953). The deflocculation of kaolinite suspensions and the accompanying change-over from positive to negative chloride adsorption. Clay Min. Bull. 2, 45-50.

Smart, P. (1967). Soil structure, mechanical properties and electron microscopy. PhD thesis, University of Cambridge.

Tovey, N. K. (1965). Determination of the swelling of kaolin samples when impregnated with methanol, acetone and a resin whilst being prepared for electron microscopy. Cambridge Soil Mechanics Report (unpublished).

\section{The design of permanent cutting slopes in stiff fissured clays}

CHANDLER, R. J. and SKEMPTON, A. W. (1973). Géotechnique 24, No. 4, 457-466.

\section{A. M. Muir Wood, Sir William Halcrow and Partners, London}

The conclusions from this Paper appear at first sight very neat and simple. I question whether, from the point of view of a practical engineer concerned with the prediction of stability of a cutting, the conclusions may not be too simple. I have these particular observations.

The assumptions about the average pore-pressure factor $r_{\mathrm{u}}$ appear unsatisfactory. Is it possible to indicate for each instance cited how reasonable the value of 0.3 may be? Cutting slopes are usually formed fairly symmetrically in clay so that it is often instructive to consider why a failure has occurred in a particular part of one side and not elsewhere. Surface topography and groundwater movement within the fissured weathered clay seem to be the principal factors causing variation in $r_{\mathrm{u}}$. Chandler (1974) has described the brecciated Lias clay as having a considerable variation in permeability with depth and this might be expected to give rise to appreciable variation in $r_{\mathrm{u}}$ of seasonal or briefer duration on account of groundwater movements. If a mechanism of gradual equilibration of long-term pore-pressures occurs, failure may be expected when the combined short-term effects, taking account of progressive failure and water pressure in joints, cause the factor of safety to drop below $1 \cdot 0$. With the increase of time, the ultimate cause of failure may be a less extreme event than would have been necessary at a previous time. Can the Authors relate the failures to specific occasions of short-term reduction in safety factor, on account, for instance, of intense or prolonged rainfall?

With the increasing awareness that the Mohr failure envelope for weak and fragmented rock, for powders, for spoil heaps and many other materials is curved convex upwards, there appears to be need of an explanation as to why such a phenomenon does not occur with some at least of the clays described. A 'brecciated fabric of lithorelicts set in a matrix of softer and disturbed clay' appears almost certain to display such a feature. At low loading, failure surfaces will develop to avoid shearing the lithorelicts whilst at higher loading these will increasingly tend to become overstressed. The data appear inadequate to compare against such a hypothesis since the lowest value of mean effective stress is an order of magnitude higher than the value 
given to $c^{\prime}$. Inspection of Figs 2 and 3 suggests that since the data relate almost entirely to effective average shear stresses of upward of $10 \mathrm{kN} / \mathrm{m}^{2}$, the evidence is inadequate to establish whether a better fit to the results would not follow from a slight increase in $\phi^{\prime}$ rather than the addition of a $c^{\prime}$ intercept since the same data were last presented by one of the Authors (Chandler, 1974). The evidence of steeper faces for relatively low heights of cut in stiff clay can surely be explained more readily by the apparent cohesion developed by pore-suction above the piezometric level, which gives rise to the capability for deep cracks to persist from the surface. A value for $c^{\prime}$ of $1.0 \mathrm{kN} / \mathrm{m}^{2}$ would be associated with cracks less than $250 \mathrm{~mm}$ deep.

In order to establish the best values for $c^{\prime}$ and $\phi^{\prime}$ to attribute to a failure in assumed homogeneous and isotropic material it is clearly necessary to show that these values applied to the mode of failure will yield a safety factor close to unity. This alone is insufficient, however; it is also necessary to show that failure has occurred along the preferred surface of failure. The Authors make no reference to this point. It is to be noted, however, that substitution of a circular surface of failure for the non-circular surface observed has required an increase in $c^{\prime}$ in order to maintain $F=1$. Thus, for the parameters used, the circular surface more nearly represents the preferred surface of failure than does the non-circular surface. This fact suggests that a better representation of the properties of the clay (if full pore-pressure equilibration be accepted) would be achieved by a circular surface of failure with $\phi^{\prime}$ increased and $c^{\prime}$ reduced.

The assumption is made throughout that these are all first-time failures. Has this description a definable significance in relation to the existence of slickensides within the upper layer of such overconsolidated clays, presumably caused by relaxation as overburden has been reduced after the period of consolidation?

Are the numbers of cases adequate in relation to the known lithological variation of the clays concerned?

It appears a little arbitrary to include Sheppey (after about 12 years) and exclude Watford (after about 10 years) where the latter falls well outside the proposed envelope. Presumably 'c. 12 years' and 'c. 10 years' could both be 11 years.

In view of its authorship this Paper may well come to be used uncritically and hence the Writer feels there is a need to ensure that it can be relied upon to provide safe criteria for design. From the content of the Paper this is not established. For the wide scatter of data for the Lias, in particular, the hypothesis appears to be open to considerable doubt.

\section{Author's reply to Muir Wood}

In reply to Mr Muir Wood's discussion on the Paper we make the following comments.

Reference to Chandler (1974) will show that pore-pressures used in the back analysis of the Lias slips are based on piezometcr obscrvations at five sites (Ardley, Barrowden, Seaton, Wothorpe B and Wothorpe C). The observations conform to a reasonably consistent pattern, as shown in Figs 4 and 5 of Chandler (1974), from which the values of $\bar{r}_{\mathrm{u}}$ have been deduced for the other sites. In Fig. 3 of the present Paper the range of uncertainty is indicated.

For London Clay the situation is less satisfactory and, as is emphasized in the Paper, more field work is needed. Nevertheless from the existing data it is concluded that $\bar{r}_{\mathrm{u}}=0.3$ is a typical value, but Fig. 2 in the Paper shows the effect on back analysis if $\vec{r}_{\mathrm{u}}$ is altered to $0 \cdot 35$ or $0 \cdot 25$. So far as present information is concerned these are probable upper and lower limits for most cutting slopes in the brown London Clay, where cquilibration is complete. We should be interested to know of any field evidence conflicting with this conclusion, or indeed of any new piezometer observations in London Clay cuttings. 
Mr Muir Wood asks if there is evidence that slips are 'triggered' by heavy rain. Chandler (1974) shows that the failures at Culworth and Heyford were preceded by periods of high rainfall, and the slip at Ardley took place in a month of heavy thunderstorms.

Over the range of effective pressure relevant to slope stability problems in cuttings there is no evidence that the failure envelope shows any curvature (see Figs 2 and 3). Whether or not the envelope, when extrapolated back to very small effective pressures, is curved or even passes through the origin is a matter for debate. The use of constant values of $c^{\prime}$ and $\phi^{\prime}$, as well as representing adequately the results of back analysis, leads to a relatively simple design procedure. On the present evidence there is no justification for adopting a curved failure envelope, with $c^{\prime}$ and $\phi^{\prime}$ as functions of effective pressure and with the considerable complications this would entail.

The choice of shear strength parameters to be associated with a circular arc analysis is explained in the Paper.

The 'mass' strength of the clay takes into account the effect of fissures, some of which may be slickensided. The Paper shows clearly that this strength, as operative in a 'first time' slide, is far greater than the residual strength which would operate in a reactivated slide along a preexisting continuous slip surface. A first-time slide therefore has a definable significance in very practical terms.

It would of course be useful to have more case records; here again we should welcome any additional data.

The difference between the slips at Sheppey and Watford (Table 2) is not in the times to failure which as Mr Muir Wood points out, are virtually the same, but in the depth of cut, that at Watford being $50 \%$ larger. It is possible, however, that Sheppey should also be included in the category of slips with incomplete equilibration of pore-pressure.

Finally, Mr Muir Wood considers that safe criteria for design have not been established. However, Figs 4 and 5 include all the data known to the Authors, and the curves for $\bar{r}_{\mathrm{u}}=0.35$ define a lower boundary to these data. It is therefore certain that in general the criteria err on the side of being over-safe. Moreover it is not suggested that $\bar{r}_{\mathrm{u}}$ can never exceed 0.35 . If in the judgement of the engineer higher values of $\bar{r}_{\mathrm{u}}$ are possible at a given site, he is at liberty to design accordingly and should do so.

\section{REFERENCE}

Chandler, R. J. (1974). Lias clay: the long-term stability of cutting slopes. Géotechnique 24, No. 1, 21-38. 